\title{
Supplementary material: Subglacial permafrost dynamics and erosion inside subglacial channels driven by surface events in Svalbard
}

Andreas Alexander ${ }^{1,2}$, Jaroslav Obu ${ }^{1}$, Thomas V. Schuler ${ }^{1}$, Andreas Kääb ${ }^{1}$, and Hanne H. Christiansen ${ }^{2}$ ${ }^{1}$ Department of Geosciences, University of Oslo, 0316 Oslo, Norway

${ }^{2}$ Department of Arctic Geology, The University Centre in Svalbard, 9171 Longyearbyen, Norway

Correspondence: Andreas Alexander (andreas.alexander@geo.uio.no)

1 Tables

Table S1. Pearson correlation coefficients for forecasted versus daily observed temperature and rainfall in the measurement periods 2016 and 2019.

\begin{tabular}{lll}
\hline & $\mathbf{2 0 1 6}$ & $\mathbf{2 0 1 9}$ \\
\hline Temperature & 0.985 & 0.986 \\
Rainfall & 0.234 & 0.339 \\
\hline
\end{tabular}

2 Figures 
(ว。) рәи.ләsqо

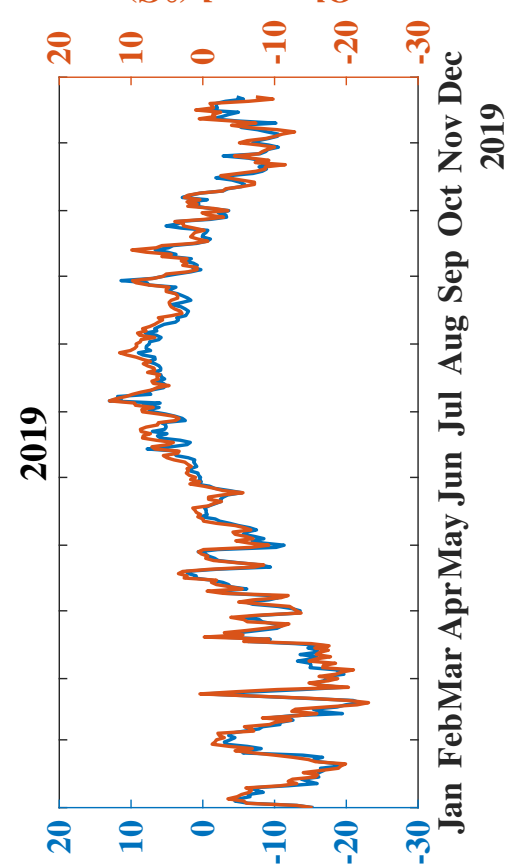

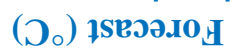

(1)

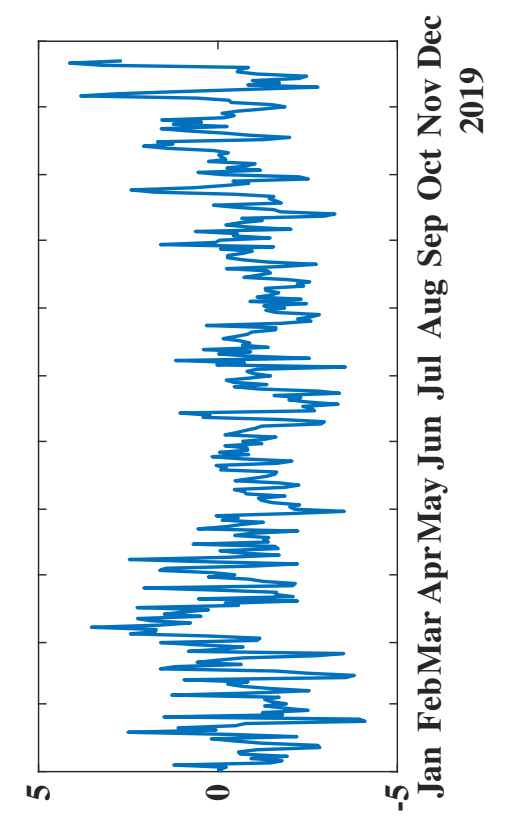

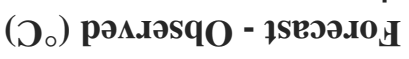

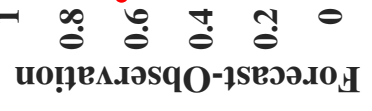

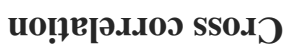

(ว。) рәл.ләsqo

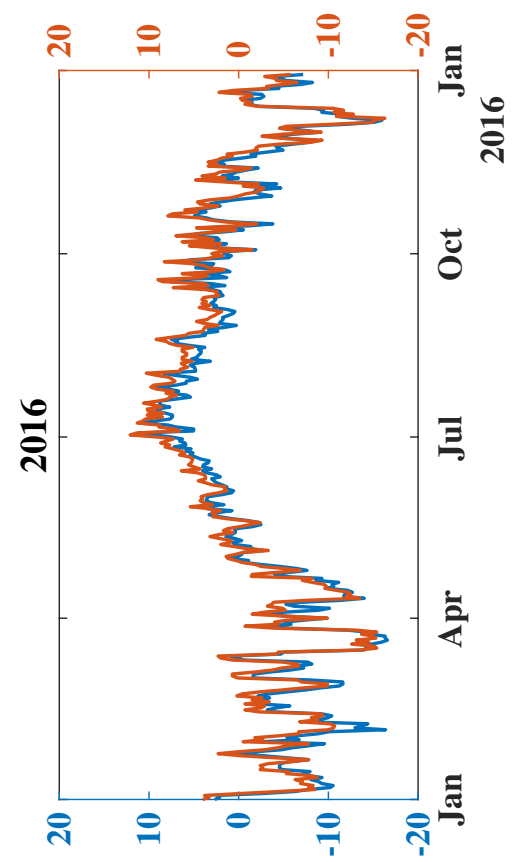

(つ。) $\mathfrak{l S B g} . \mathrm{IO}_{\mathrm{H}}$

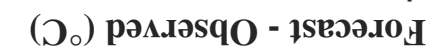

$\Xi$

安

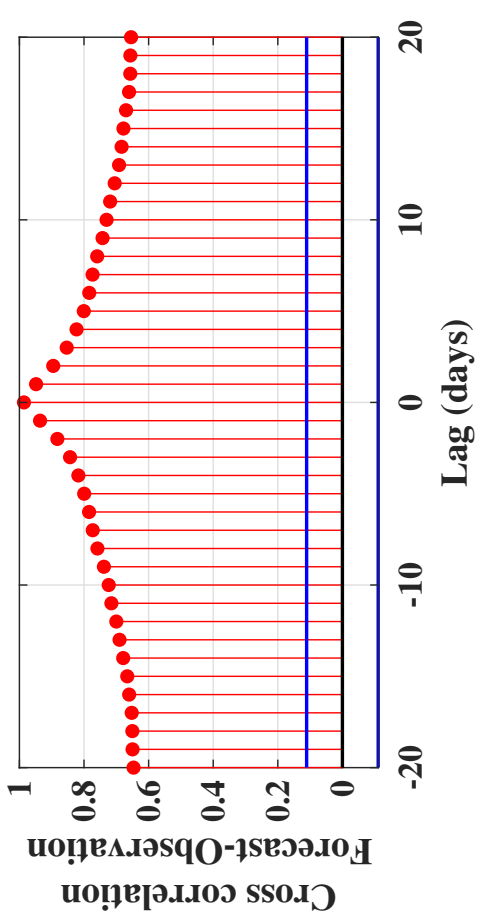

递

o
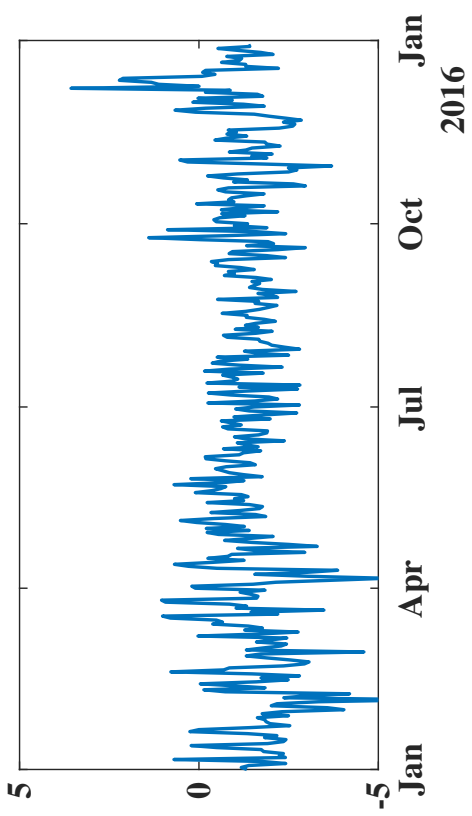

$\stackrel{\infty}{\oplus} \stackrel{0}{0}$ ப்

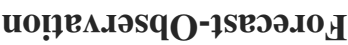

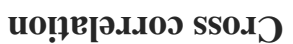

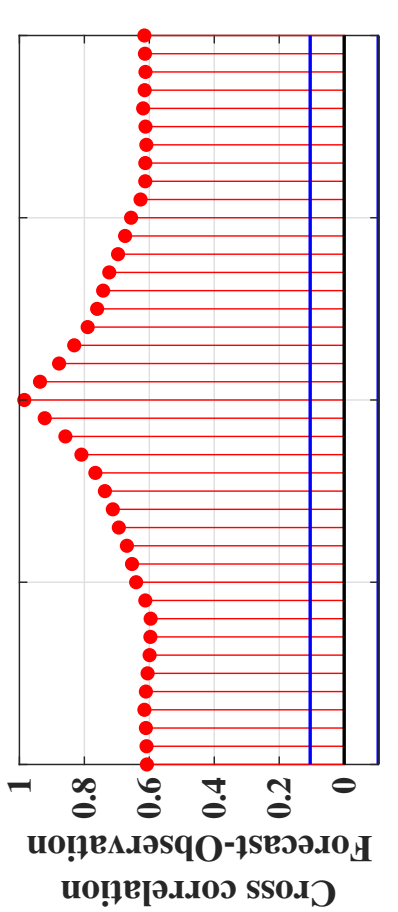

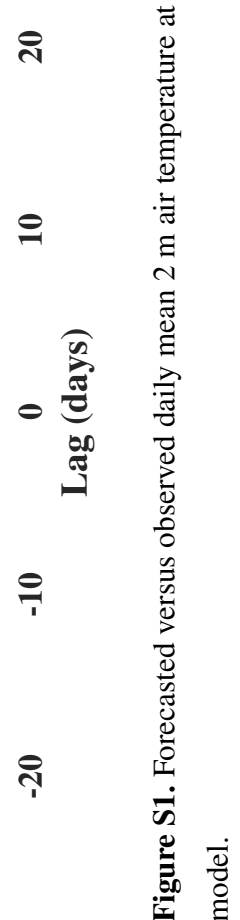




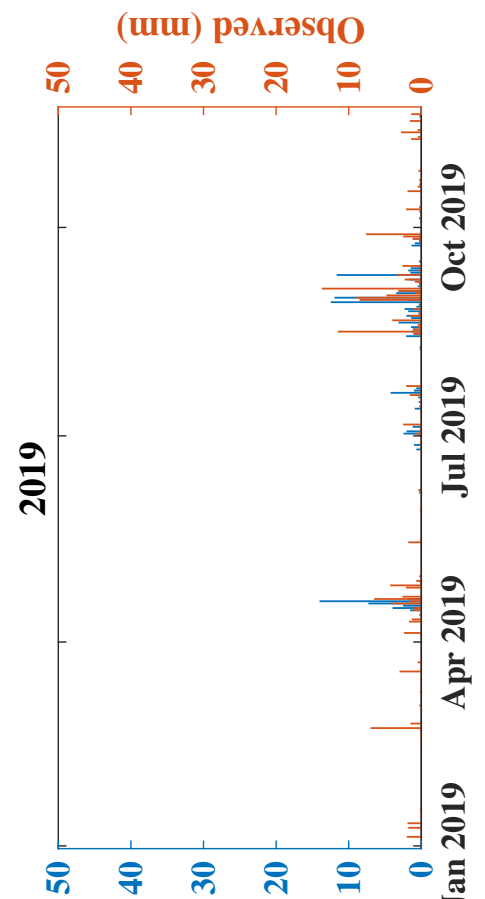

(uய) 1 S6อว.10

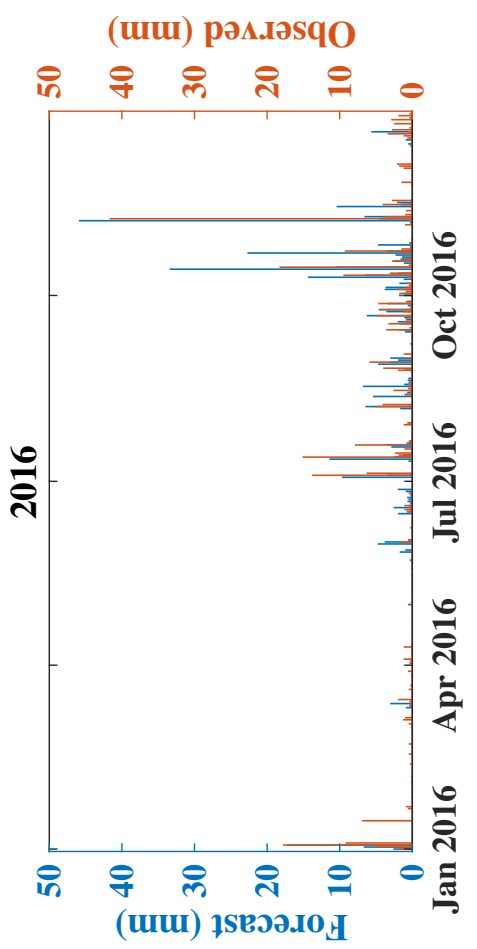

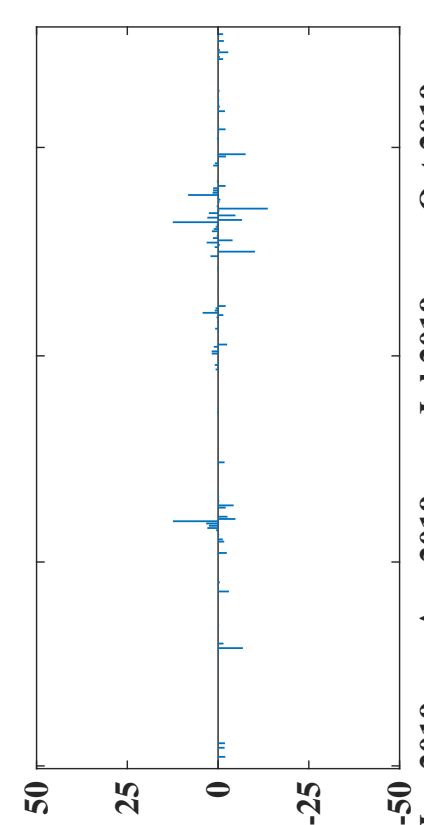

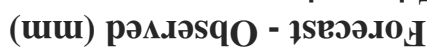

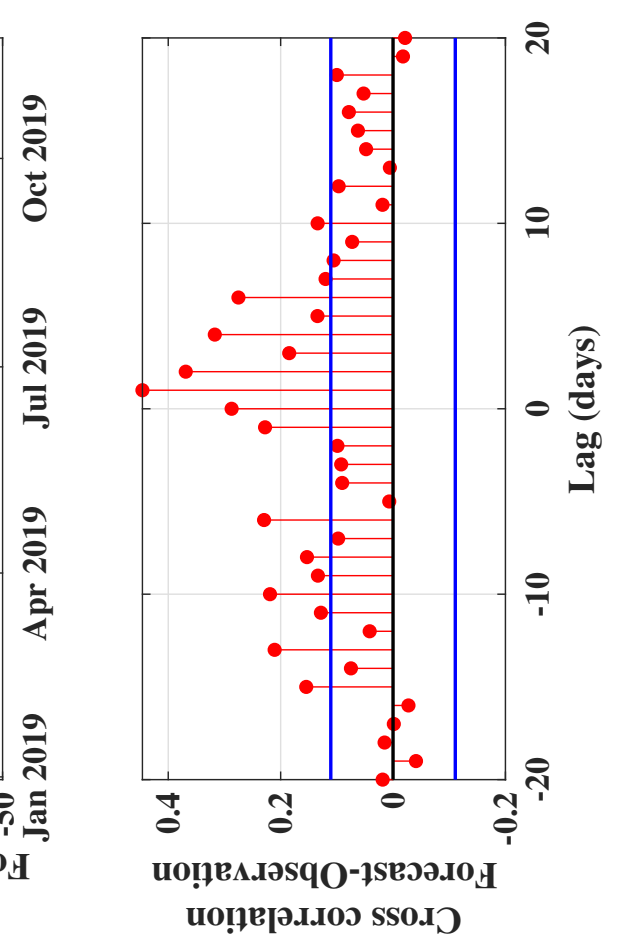

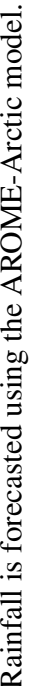

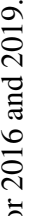
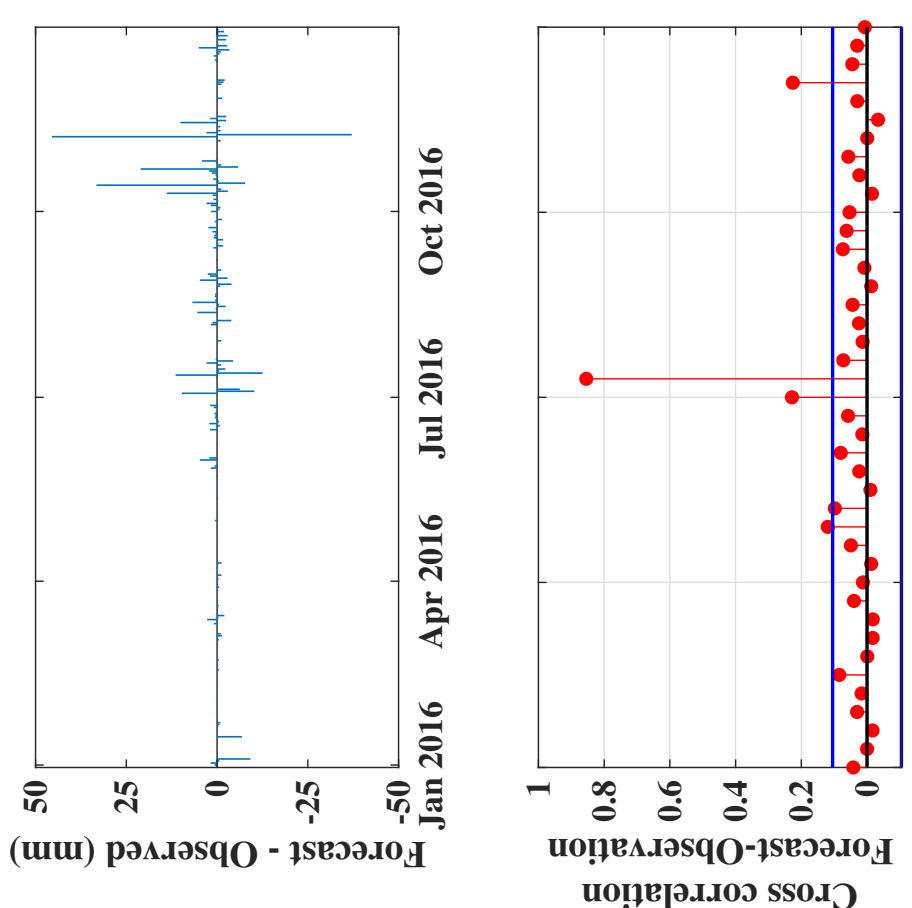

구

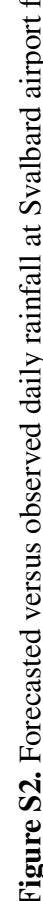




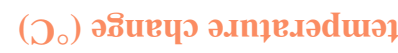

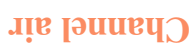

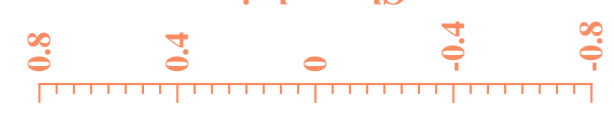

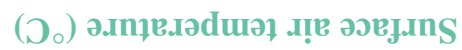

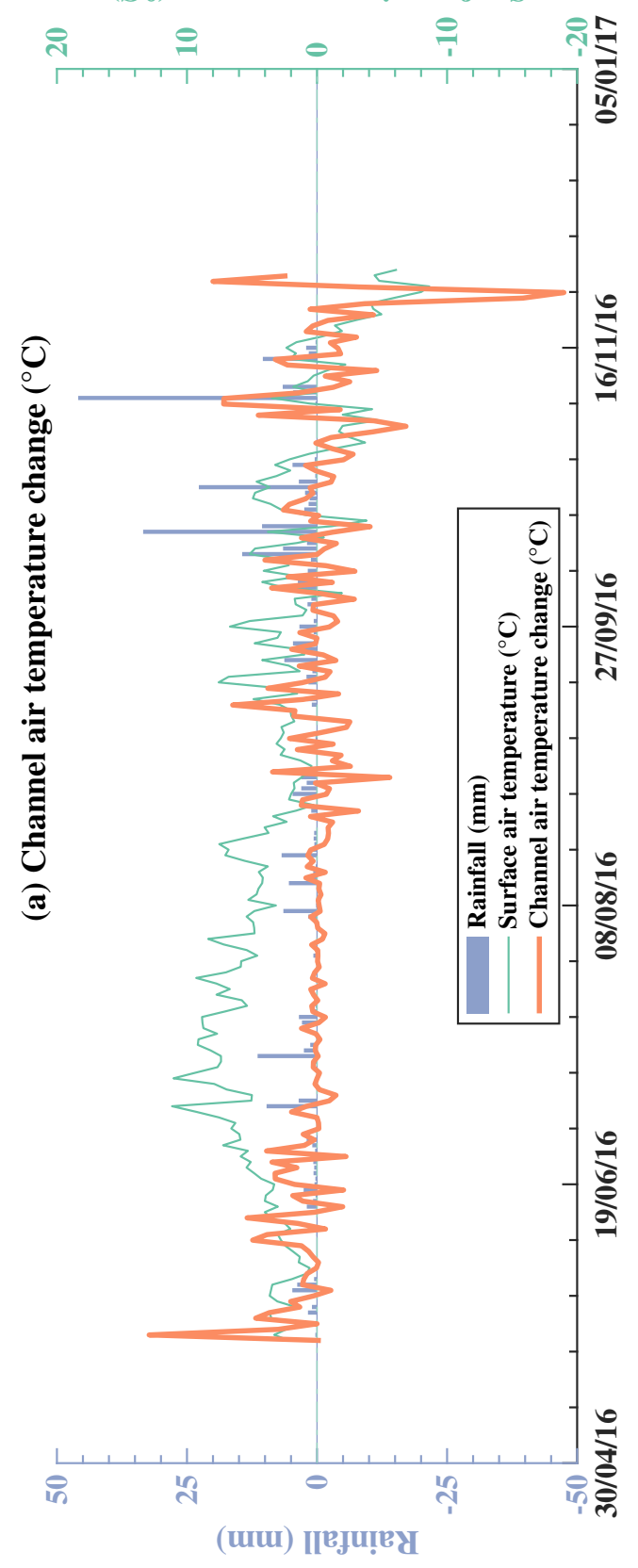

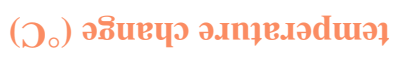

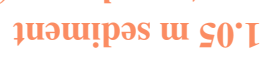

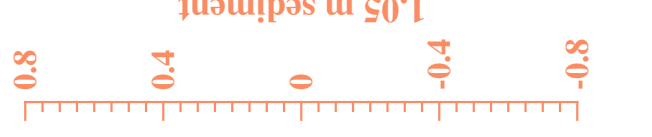

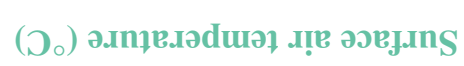

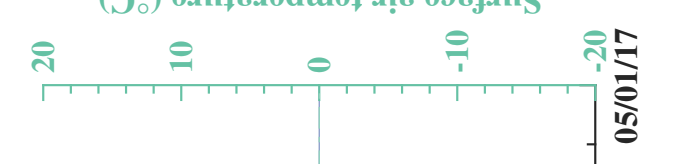

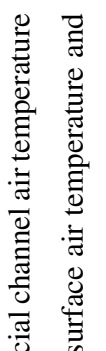

$\frac{\pi}{00}$

잉

$\stackrel{0}{0}$

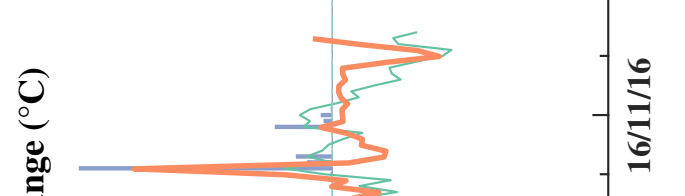

芩

กิร

ำ

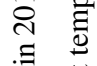

离

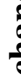

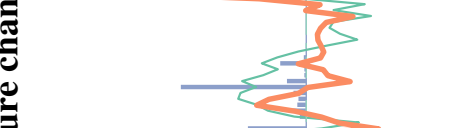

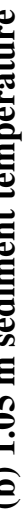

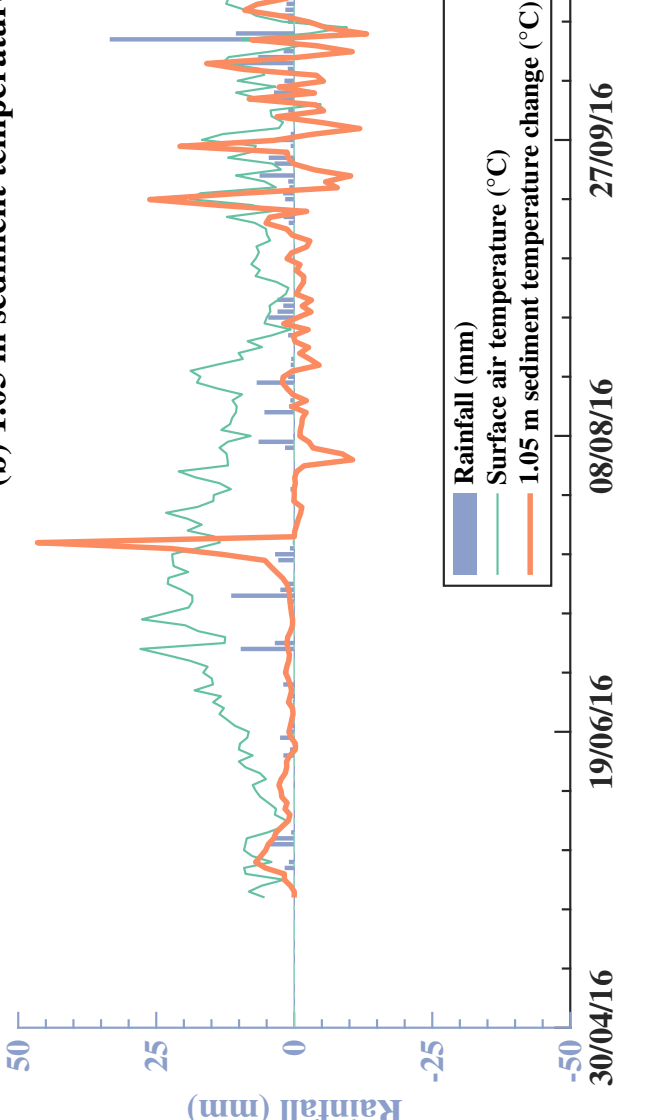

吾

苛

过

范

总 苛

产

हี

品

స్

善

를 छ

$\frac{\pi}{\pi}$

总

की

ले

की 